\title{
Duodenal stump reinforcement might reduce both incidence and severity of duodenal stump leakage after laparoscopic gastrectomy with Roux-en-Y reconstruction for gastric cancer
}

\author{
Motonari $\mathrm{Ri}^{1} \cdot \mathrm{Naoki} \mathrm{Hiki}^{1}$ (D) Naoki Ishizuka ${ }^{2} \cdot$ Satoshi Ida $^{1} \cdot \mathrm{Koshi} \mathrm{Kumagai}^{1} \cdot$ Souya Nunobe $^{1} \cdot$ Manabu Ohashi $^{1}$. \\ Takeshi Sano ${ }^{1}$
}

Received: 25 December 2018 / Accepted: 23 February 2019 / Published online: 9 March 2019

(c) The International Gastric Cancer Association and The Japanese Gastric Cancer Association 2019

\begin{abstract}
Background Although duodenal stump leakage (DSL) is a relatively rare complication after gastrectomy with Roux-en-Y (R-Y) reconstruction, it is difficult to treat and can be fatal. We investigated the impact of duodenal stump reinforcement on DSL after laparoscopic gastrectomy with R-Y reconstruction for gastric cancer.

Methods This retrospective study of 965 patients with gastric cancer who underwent laparoscopic distal or total gastrectomy (LDG or LTG) with R-Y reconstruction compared surgical outcomes between two groups, the duodenal stump reinforcement group (reinforcement group) $(n=895)$ and that without duodenal stump reinforcement (non-reinforcement group) $(n=70)$. Results Mean operative duration was significantly longer in the reinforcement than in the non-reinforcement group (LDG; $291 \mathrm{~min}$ versus $258 \mathrm{~min}, p<0.001$, LTG; $325 \mathrm{~min}$ versus $285 \mathrm{~min}, p<0.001$ ). DSL occurred less frequently in the reinforcement than in the non-reinforcement group $(0.67 \%$ vs. $5.71 \%, p<0.001)$. Furthermore, non-reinforcement was an independent risk factor for DSL in multiple logistic regression analysis with adjustment for potential confounding factors. Patients with DSL in the non-reinforcement group all required re-operation, while all but one patient with DSL in the reinforcement group recovered with conservative management.

Conclusions Duodenal stump reinforcement in laparoscopic gastrectomy with R-Y reconstruction may reduce the risk of DSL development and minimize its severity.
\end{abstract}

Keywords Duodenal stump leakage $\cdot$ Duodenal stump reinforcement $\cdot$ Roux-en-Y reconstruction $\cdot$ Laparoscopic distal gastrectomy $\cdot$ Laparoscopic total gastrectomy

\section{Introduction}

Minimally invasive gastrectomy was first reported in 1994 [1]. The safety and feasibility of laparoscopic gastrectomy (LG) for gastric cancer have since been shown in recent studies [2-5]. Therefore, LG has been increasingly performed as curative treatment for gastric cancer.

Naoki Hiki

naoki.hiki@jfcr.or.jp

1 Department of Gastroenterological Surgery, Cancer Institute Hospital, Japanese Foundation for Cancer Research, 3-8-31 Ariake, Koto-ku, Tokyo 135-8550, Japan

2 Department of Clinical Trial Planning and Management, Cancer Institute Hospital, Japanese Foundation for Cancer Research, Tokyo, Japan
Among several representative procedures, there are various types of reconstruction after LG such as Billroth I (B-I), Billroth II (B-II) and Roux-en-Y (R-Y) reconstruction. The most widely used type of reconstruction after gastrectomy varies by country, with B-I or R-Y reconstruction often being performed after stomach resection in Japan. Furthermore, of these, B-II and R-Y are the only reconstructions that result in the formation of a blind end of the duodenum.

Postoperative complications with R-Y reconstruction particularly include duodenal stump leakage (DSL) and internal herniation through the transected mesentery and mesocolon [6]. Although DSL is a relatively rare postoperative complication, it can be difficult to treat and is fatal in some cases. Possible causes of DSL include inadequate or no reinforcement of the duodenal stump, duodenal wall inflammation, devascularization, cancer involvement at the resection line and so on [7]. In addition, exposed bile and pancreatic juice, 
which mix together to produce powerful digestive forces, dissolve the arterial walls close to the duodenal stump resulting in pseudoaneurysm formation. Sudden major bleeding involving the pseudoaneurysm may then occur.

Duodenal stump reinforcement has occasionally been performed for prevention of DSL in laparotomy-type surgery [8]. However, it is rather difficult to manually reinforce the duodenal stump during laparoscopic surgery. We have developed a safe technique employing a buried suture for the duodenal stump, with the formation of an invagination and release of pressure at the edge of the stump during laparoscopic surgery.

Herein, we introduce our duodenal reinforcement methods along with an assessment of how duodenal reinforcement influences DSL in laparoscopic gastrectomy/R-Y reconstruction.

\section{Patients and methods}

\section{Patients}

From July 2005 to June 2016, 1040 consecutive patients with gastric cancer underwent laparoscopic distal gastrectomy (LDG) or laparoscopic total gastrectomy (LTG) with $\mathrm{R}-\mathrm{Y}$ reconstruction at the Department of Gastroenterological Surgery, Cancer Institute Hospital, Tokyo, Japan. We enrolled patients with confirmation in their operative records of whether or not duodenal stump reinforcement had been performed. Ultimately, 965 patients were included in the present study. We collected the patient characteristics and surgical details from our database and information contained in electronic medical records including the presence or absence of duodenal stump reinforcement. Whether to perform reinforcement had been decided by the primary surgeon. Clinical stages were determined according to the International Union Against Cancer (UICC) classification system. The severity of postoperative complications was evaluated according to the Clavien-Dindo classification (C-D). Complications of C-D grade $\geq 3$ a were regarded as events.

\section{Intraoperative duodenal stump reinforcement}

In all cases, the end of the duodenal side was resected employing an automatic suturing device. Then, the duodenal stump was laparoscopically buried, with suturing performed by hand. As a specific buried suture technique in laparoscopic surgery, first, one stitch was placed across the center of the duodenal stump by the operator on the right side of the patient. The edge of the duodenal stump on the lesser curvature side was pushed and fully inverted prior to ligation, by the assistant, using two-handed forceps. Then, ligation was performed outside of the port (Fig. 1a). Next, this edge was easily covered by buried suturing of the sero-muscular layer (Fig. 1b). Third, another edge of the duodenal stump was also sufficiently inverted, by the assistant, with right-handed forceps, and then totally covered employing similar suturing by the operator (Fig. 1c). Finally, a few stitches, if necessary, were added to the staple line for reinforcement (Fig. 1d).

\section{Statistical methods}

All continuous variables are expressed as the median. Statistical analyses were conducted using the Mann-Whitney $U$ test, Student's $t$ test and the Chi square test or Fisher's exact test to compare clinical characteristics and surgical outcomes between study groups. Multiple logistic regression analysis was performed to estimate the association between DSL and duodenal stump reinforcement with adjustment for potential confounding factors. Due to the low number of events of DSL, these factors could not be included into the model simultaneously. A $p$ value of 0.05 was considered to indicate a statistically significant difference. All statistical analyses were performed with JMP Pro 13 (SAS Institute Japan Ltd, Japan) for windows.

\section{Results}

\section{Patient characteristics}

Overall patient characteristics are shown in Table 1 $(n=965) .895$ patients underwent gastrectomy with duodenal stump reinforcement (reinforcement group) and the remaining 70 underwent gastrectomy without duodenal stump reinforcement (non-reinforcement group).

The rates of ASA (American Society of Anesthesiologists) score $\geq 2$, history of laparotomy and cStage IB or more were higher in the reinforcement group, while the rates of male gender and LTG were higher in the non-reinforcement group.

\section{Operative and early postoperative outcomes}

Table 2 shows perioperative outcomes including the rate of DSL. Operative durations were longer in the reinforcement than in the non-reinforcement group. The rate of DSL was $1.0 \%(10 / 965)$ in all patients and was significantly lower in the reinforcement $(0.67 \%)$ than in the non-reinforcement (5.7\%) group $(p<0.01)$.

\section{Logistic regression analysis of risk factors for DSL}

Logistic regression analysis results related to the occurrence of DSL are shown in Table 3. In univariate analysis (Table 3a), sex, body mass index $\geq 23 \mathrm{~kg} / \mathrm{m}^{2}$, intraoperative 
Fig. 1 Illustrations of performing duodenal stump reinforcement. a One stitch is placed across the center of the staple line of the duodenum by the operator on the right side of the patient. The ligation is then performed outside of the port after one edge of the duodenal stump on the lesser curvature side has been fully inverted by the assistant, employing forceps. b The inverted edge of the duodenal stump is covered by buried suturing of the sero-muscular layer. c Another edge of the duodenal stump is also fully inverted with right-handed forceps, by the assistant, followed by total coverage employing similar suturing by the operator. d A few stitches are added to the staple line, if needed, and the duodenal stump reinforcement is thereby completed
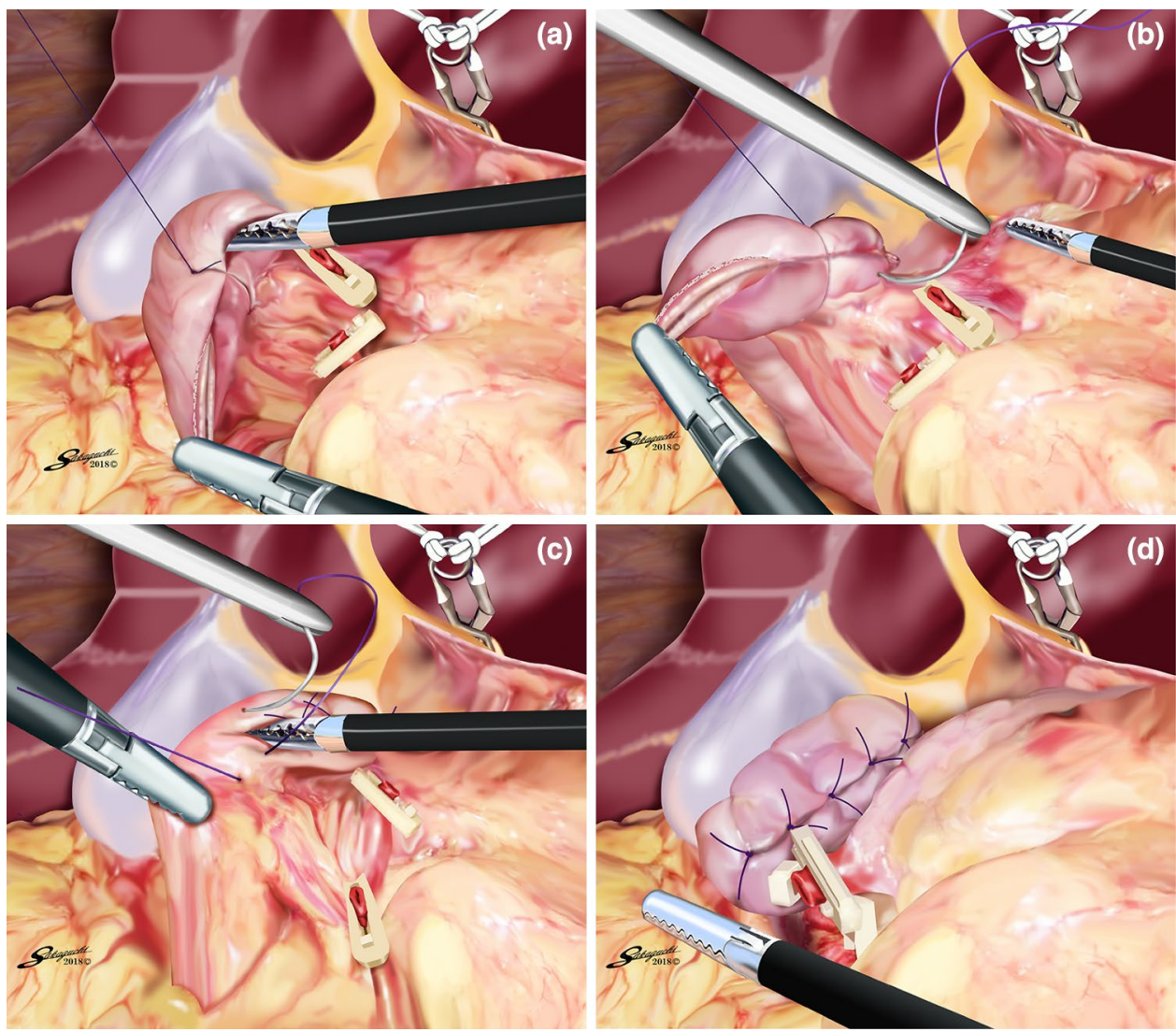

blood loss $\geq 30 \mathrm{ml}$ and non-reinforcement of the duodenal stump were significant risk factors. In multivariate analysis with adjustment for potential confounding factors (Table $3 b$ ), non-reinforcement of the duodenal stump was identified as the significant independent risk factor for the onset of DSL.

\section{Details of patients with DSL}

Table 4 details the ten patients developing DSL. DSL occurred in the early postoperative period in the non-reinforcement group, and all cases required re-operation, while in the reinforcement group DSL occurred secondary to other complications and all but one patient recovered with conservative management.

\section{Discussion}

In the present study, duodenal stump reinforcement can be safely performed and significantly decreased the incidence of postoperative DSL in patients undergoing laparoscopic gastrectomy with R-Y reconstruction. In addition, all the DSL cases in the non-reinforcement group required re-operation, whereas DSL in the reinforced group was successfully managed conservatively in more than $80 \%$ of cases. This result suggests that even if DSL occurs, its severity can be decreased by duodenal stump reinforcement.

DSL has several causes, as noted above. Paik et al. reported that gastric outlet obstruction before surgery was a significant risk factor for DSL due to inflammation of the surrounding duodenal wall tissue [9]. In addition, the staple line itself in patients requiring re-operation was actually intact in our study. Given these observations, DSL is thought to be attributable to collapse of the duodenal wall very near the staple line due to wall tissue vulnerability or peristaltic pressure loading onto the blind duodenal stump. Therefore, to prevent DSL, it is considered to be important to bury the staple line and its surrounding tissue sufficiently to assure that pressure on the duodenal wall just below the staple line can be released, rather than increasing the strength of the staple line itself.

On the other hand, even in cases with a reinforced duodenal stump, DSL occurred, although less frequently. DSL in the reinforcement group was preceded by other complications such as pancreatic fistula and abdominal abscess. These additional complications other than DSL could have been the causes of perforation. Pancreatic juice can digest the tissues around the duodenal stump. Furthermore, the contents of an abscess can escape into the lumen of the duodenum beyond the duodenal stump including the suture line. These pathophysiological mechanisms could, 
Table 1 Patient characteristics

\begin{tabular}{|c|c|c|c|}
\hline & $\begin{array}{l}\text { Reinforcement group } \\
(n=895)\end{array}$ & $\begin{array}{l}\text { Non-reinforcement } \\
\text { group }(n=70)\end{array}$ & $p$ value \\
\hline Sex, $n(\%)$ & & & $<0.01$ \\
\hline Male & $626(70)$ & $60(86)$ & \\
\hline Female & $269(30)$ & $10(14)$ & \\
\hline Age, years (range) & $66(26-90)$ & $65(39-83)$ & 0.50 \\
\hline ASA Score, $n(\%)$ & & & 0.04 \\
\hline 1 & $407(45)$ & $41(58)$ & \\
\hline $2 \leq$ & 488 (55) & $29(42)$ & \\
\hline Body mass index, kg/m² (range) & $22.9(14.5-39.1)$ & $23.2(18.2-32.9)$ & 0.49 \\
\hline Preoperative prealbumin, $\mathrm{mg} / \mathrm{dl}$ (range) & $27.4(12.6-49.7)$ & $28.7(15.2-39.9)$ & 0.50 \\
\hline Preoperative albumin, g/dl (range) & $4.1(2.9-4.9)$ & $4.2(3.6-4.8)$ & 0.22 \\
\hline History of laparotomy, $n(\%)$ & $179(20)$ & $7(10)$ & 0.04 \\
\hline Location, $n(\%)$ & & & 0.09 \\
\hline Lower & $174(20)$ & $8(11)$ & \\
\hline Others & $721(80)$ & $62(89)$ & \\
\hline cStage, $n(\%)$ & & & $<0.001$ \\
\hline IA & $771(86)$ & $70(100)$ & \\
\hline $\mathrm{IB} \leq$ & $124(14)$ & $0(0)$ & \\
\hline Type of gastrectomy, $n(\%)$ & & & $<0.001$ \\
\hline LDG & $725(81)$ & $32(46)$ & \\
\hline LTG & $170(19)$ & $38(54)$ & \\
\hline Lymph node dissection, $n(\%)$ & & & 0.14 \\
\hline$\leq \mathrm{D} 1+$ & $731(82)$ & $62(89)$ & \\
\hline D2 & 164 (18) & $8(11)$ & \\
\hline
\end{tabular}

$L D G$ laparoscopic distal gastrectomy, $L T G$ laparoscopic total gastrectomy

Table 2 Surgical outcomes and postoperative morbidities

\begin{tabular}{llcc}
\hline & $\begin{array}{l}\text { Reinforcement group } \\
(n=895)\end{array}$ & $\begin{array}{l}\text { Non-reinforcement } \\
\text { group }(n=70)\end{array}$ & $p$ value \\
\hline Operative duration for LDG, min (range) & $291(155-633)$ & $258(154-335)$ & $<0.001$ \\
Operative duration for LTG, min (range) & $325(192-655)$ & $285(197-382)$ & $<0.001$ \\
Intraoperative blood loss, ml (range) & $30(0-1050)$ & $30(0-700)$ & 0.35 \\
Duodenal stump leakage, $n(\%)$ & $6(0.67)$ & $4(5.7)$ & $<0.001$ \\
Intra-abdominal abscess, $n(\%)$ & $48(5.4)$ & $6(8.6)$ & 0.26 \\
Pancreatic fistula, $n(\%)$ & $12(1.3)$ & $0(0)$ & 0.32 \\
\hline
\end{tabular}

Clavien-Dindo classification (C-D). C-D grade $\geq 3$ a regarded as an event

$L D G$ laparoscopic distal gastrectomy, $L T G$ laparoscopic total gastrectomy hypothetically, result in delayed DSL in the reinforcement group. In addition, DSL occurred 3 days after surgery on average in the non-reinforcement group free of prior complications, while the onset was 20 days in the reinforcement group with prior complications. The late onset of DSL in the reinforcement group during the postoperative period also supports these hypotheses. DSL in the reinforcement group was conservatively managed in all but one case, indicating the underlying mechanisms to differ from that of DSL in the non-reinforcement group requiring re-operation. Only one patient, who underwent reinforcement of the duodenal stump but required re-operation, had an unusually critical postoperative course. This patient developed severe complications including necrotic pancreatitis and intra-abdominal bleeding and underwent re-operation twice prior to the onset of DSL. Given these observations, very serious patient comorbidities might contribute to DSL in the reinforcement group.

The DSL occurrence rate was $1.0 \%$ overall in the present study. The incidence of DSL after gastric resection has been suggested to be higher in laparoscopic surgery than in open gastrectomy [10-12]. Kostakis et al., based on a systematic review, reported the highest postoperative DSL frequency 
Table 3 Logistic regression analysis of risk factors for DSL

(a) Univariate analysis

Odds ratio

1.00

0.64

$<66$ years

$\geq 66$ years

Gender

Male

Female

ASA Score

$<2$

$\geq 2$

Body mass index

$<23 \mathrm{~kg} / \mathrm{m}^{2}$

$\geq 23 \mathrm{~kg} / \mathrm{m}^{2}$

Preoperative prealbumin

$$
<27.5 \mathrm{mg} / \mathrm{dl}
$$$$
\geq 27.5 \mathrm{mg} / \mathrm{dl}
$$

Preoperative albumin

$<4.1 \mathrm{~g} / \mathrm{dl}$

$\geq 4.1 \mathrm{~g} / \mathrm{dl}$

History of laparotomy

Absent

Present

Location

Lower

Others

cStage

IA

$\geq$ IB

Type of operation

LDG

LTG

Lymph node dissection

$<$ D2

D2

Operative duration

$$
<294 \text { min }
$$

$\geq 294 \mathrm{~min}$

Intraoperative blood loss

$$
<30 \mathrm{ml}
$$$$
\geq 30 \mathrm{ml}
$$

Reinforcement of duodenal stump

Present

Absent

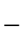

$-$

1.00

2.03

1.00

9.52

1.00

2.33

1.00

1.07

1.00

1.04

$-$

$-$

1.00

2.95

1.00

1.56

1.00

3.12

1.00

2.32

1.00

6.91

1.00

8.97
95\% CI

$p$ value

0.18-2.29

0.49

$0.52-7.92$

$1.20-75.4$

$<0.01$

0.59-9.07

0.2

$0.30-3.83$

0.91

$0.22-4.97$

0.95

$-$

$0.75-11.5$

$0.40-6.11$

0.51

$0.87-11.1$

0.06

0.59-9.05

0.2

$0.87-54.8$

0.03 
Table 3 (continued)

(b) Multivariate analysis for evaluating relationship between DSL and duodenal stump reinforcement with adjustment for potential confounding factors

\begin{tabular}{|c|c|c|c|}
\hline & Odds ratio & $95 \% \mathrm{CI}$ & $p$ value \\
\hline \multicolumn{4}{|l|}{ Gender } \\
\hline Male & - & - & \\
\hline Female & - & - & - \\
\hline \multicolumn{4}{|c|}{ Reinforcement of duodenal stump } \\
\hline Present & 1.00 & & \\
\hline Absent & 7.38 & $2.02-26.9$ & $<0.01$ \\
\hline \multicolumn{4}{|c|}{ Body mass index } \\
\hline$<23 \mathrm{~kg} / \mathrm{m}^{2}$ & 1.00 & & \\
\hline$\geq 23 \mathrm{~kg} / \mathrm{m}^{2}$ & 9.26 & $1.16-73.8$ & 0.03 \\
\hline \multicolumn{4}{|c|}{ Reinforcement of duodenal stump } \\
\hline Present & 1.00 & & \\
\hline Absent & 8.67 & $2.35-31.9$ & $<0.01$ \\
\hline \multicolumn{4}{|l|}{ cStage } \\
\hline IA & 1.00 & & \\
\hline$\geq \mathrm{IB}$ & 6.34 & $1.26-31.8$ & 0.02 \\
\hline \multicolumn{4}{|c|}{ Reinforcement of duodenal stump } \\
\hline Present & 1.00 & & \\
\hline Absent & 15.50 & $3.40-70.7$ & $<0.001$ \\
\hline \multicolumn{4}{|c|}{ Lymph node dissection } \\
\hline$<\mathrm{D} 2$ & 1.00 & & \\
\hline D2 & 3.87 & $1.04-14.4$ & 0.04 \\
\hline \multicolumn{4}{|c|}{ Reinforcement of duodenal stump } \\
\hline Present & 1.00 & & \\
\hline Absent & 10.50 & $2.81-39.4$ & $<0.001$ \\
\hline \multicolumn{4}{|c|}{ Intraoperative blood loss } \\
\hline$<30 \mathrm{ml}$ & 1.00 & & \\
\hline$\geq 30 \mathrm{ml}$ & 6.24 & $0.78-49.8$ & 0.08 \\
\hline \multicolumn{4}{|c|}{ Reinforcement of duodenal stump } \\
\hline Present & 1.00 & & \\
\hline Absent & 8.09 & $2.21-29.6$ & $<0.01$ \\
\hline
\end{tabular}

$D S L$ duodenal stump leakage, $L D G$ laparoscopic distal gastrectomy, $L T G$ laparoscopic total gastrectomy

Table 4 Details of patients with DSL

\begin{tabular}{lllllllll}
\hline No. & Gender & Age, years & $\begin{array}{l}\text { Body mass } \\
\text { index, }\left(\mathrm{kg} / \mathrm{m}^{2}\right)\end{array}$ & Operation & $\begin{array}{l}\text { Reinforcement of } \\
\text { duodenal stump }\end{array}$ & Time of diagnosis & Pre-existing complication & Re-operation \\
\hline 1 & Male & 61 & 24.3 & LDG & - & POD 6 & - & + \\
2 & Male & 56 & 23.5 & LDG & - & POD 2 & - & Anastomotic leakage \\
3 & Male & 69 & 23.1 & LTG & - & POD 24 & + \\
4 & Male & 76 & 24.2 & LTG & - & POD 2 & - & + \\
5 & Male & 62 & 23.4 & LDG & + & POD 13 & Necrotic pancreatitis, etc. \\
6 & Male & 75 & 24.2 & LDG & + & POD 29 & Intra-abdominal abscess & - \\
7 & Male & 65 & 24.3 & LDG & + & POD 22 & Intra-abdominal abscess & - \\
8 & Male & 72 & 22.5 & LDG & + & POD 23 & Pancreatic fistula \\
9 & Male & 64 & 29.6 & LDG & + & POD 13 & Pancreatic fistula & - \\
10 & Male & 59 & 23.1 & LTG & + & POD 7 & - & - \\
\hline
\end{tabular}

$D S L$ duodenal stump leakage, $L D G$ laparoscopic distal gastrectomy, $L T G$ laparoscopic total gastrectomy 
of $9.1 \%$ in open and $18.3 \%$ in laparoscopic surgery [10]. Compared to other reports including laparotomy cases [7, 8, 12-14], the DSL incidence rates in this study were low, at slightly less than $6.0 \%$ if the duodenal stump was not reinforced, and remarkably low at just $0.67 \%$ when reinforced. Since our institution is a high-volume center in Japan with a large number of cases, such social factors may have influenced surgical outcomes.

The operative duration was extended by $33 \mathrm{~min}$ for LDG and by $40 \mathrm{~min}$ for LTG in the reinforcement group as compared to the non-reinforcement group. The high rate of lymph node dissection of D2 for locally advanced cancer and history of laparotomy, as well as the amount of time required for reinforcing the duodenal stump, may all contribute to prolongation of the operative time.

This study has limitations. First, there were no clear criteria for performing reinforcement of the duodenal stump and whether or not to perform reinforcement had been decided by the surgeon. Although patient factors such as tissue vulnerability and potential risks of pancreatic juice exposure might have influenced the surgeon's decision, given that nearly all of the procedures for the non-reinforcement group were performed in the first half of the research period, the decision was considered to have been made by the surgeon based on the initial policy. Furthermore, none of the DSL cases showed duodenal tumor invasion and the margin for reinforcement with a buried suture was maintained. If a sufficient margin for invagination cannot be obtained, it may be better to choose another method of reinforcing the duodenal stump such as covering the stump with a jejunal patch. Second, the small number of events makes statistical analysis less meaningful. The DSL-preventing effect of reinforcing the duodenal stump needs to be retrospectively confirmed by a multicenter study with a large sample size.

\section{Conclusion}

Duodenal stump reinforcement, a safe technique for laparoscopic gastrectomy with R-Y reconstruction, may reduce the incidence of DSL. In addition, even if DSL occurs, duodenal stump reinforcement might lessen its severity.

Funding The authors declare that this study have no external funding.

\section{Compliance with ethical standards}

Conflict of interest The authors have no conflict of interest to declare.

Human rights statement All procedures followed were in accordance with the ethical standards of the institutional and national committees governing human experimentation and in compliance with the Helsinki Declaration of 1964 and later versions.
Informed consent Informed consent or an appropriate substitute was obtained from all patients prior to their inclusion in the study.

\section{References}

1. Kitano S, Iso Y, Moriyama M, Sugimachi K. Laparoscopy-assisted Billroth I gastrectomy. Surg Laparosc Endosc. 1994;4:146-8.

2. Xiong JJ, Nunes QM, Huang W, Tan CL, Ke NW, Xie SM, et al. Laparoscopic vs open total gastrectomy for gastric cancer: a metaanalysis. World J Gastroenterol. 2013;19:8114-32.

3. Vinuela EF, Gonen M, Brennan MF, Coit DG, Strong VE. Laparoscopic versus open distal gastrectomy for gastric cancer: a meta-analysis of randomized controlled trials and high-quality nonrandomized studies. Ann Surg. 2012;255:446-56.

4. Haverkamp L, Weijs TJ, van der Sluis PC, van der Tweel I, Ruurda JP, van Hillegersberg R. Laparoscopic total gastrectomy versus open total gastrectomy for cancer: a systematic review and metaanalysis. Surg Endosc. 2013;27:1509-20.

5. Zeng YK, Yang ZL, Peng JS, Lin HS, Cai L. Laparoscopy-assisted versus open distal gastrectomy for early gastric cancer: evidence from randomized and nonrandomized clinical trials. Ann Surg. 2012;256:39-52.

6. Kumagai K, Hiki N, Nunobe S, Jiang X, Kubota T, Aikou S, et al. Different features of complications with Billroth-I and Roux-enY reconstruction after laparoscopy-assisted distal gastrectomy. J Gastrointest Surg. 2011;15:2145-52.

7. Cozzaglio L, Coladonato M, Biffi R, Coniglio A, Corso V, Dionigi $\mathrm{P}$, et al. Duodenal fistula after elective gastrectomy for malignant disease: an Italian retrospective multicenter study. J Gastrointest Surg. 2010;14:805-11.

8. Orsenigo E, Bissolati M, Socci C, Chiari D, Muffatti F, Nifosi $\mathrm{J}$, et al. Duodenal stump fistula after gastric surgery for malignancies: a retrospective analysis of risk factors in a single centre experience. Gastric Cancer. 2014;17:733-44.

9. Paik HJ, Lee SH, Choi CI, Kim DH, Jeon TY, Kim DH, et al. Duodenal stump fistula after gastrectomy for gastric cancer: risk factors, prevention, and management. Ann Surg Treat Res. 2016;90:157-63.

10. Kostakis ID, Alexandrou A, Armeni E, Damaskos C, Kouraklis G, Diamantis T, et al. Comparison between minimally invasive and open gastrectomy for gastric cancer in Europe: a systematic review and meta-analysis. Scand J Surg. 2017;106:3-20.

11. Orsenigo E, Di Palo S, Tamburini A, Staudacher C. Laparoscopyassisted gastrectomy versus open gastrectomy for gastric cancer: a monoinstitutional Western center experience. Surg Endosc. 2011;25:140-5.

12. Sarela AI. Entirely laparoscopic radical gastrectomy for adenocarcinoma: lymph node yield and resection margins. Surg Endosc. 2009;23:153-60.

13. Ali BI, Park CH, Song KY. Outcomes of non-operative treatment for duodenal stump leakage after gastrectomy in patients with gastric cancer. J Gastric Cancer. 2016;16:28-33.

14. Kim KH, Kim MC, Jung GJ. Risk factors for duodenal stump leakage after gastrectomy for gastric cancer and management technique of stump leakage. Hepatogastroenterology. 2014;61:1446-53.

Publisher's Note Springer Nature remains neutral with regard to jurisdictional claims in published maps and institutional affiliations. 